\title{
Factors Increasing the Risk of Recurrence in Fistula-in-ano
}

\author{
Nabiyah Bakhtawar ${ }^{1}$, Muhammad Usman ${ }^{2}$ \\ 1. Surgery, Lister Hospital, Stevenage, GBR 2. Internal Medicine, Jinnah Hospital, Lahore, PAK \\ Corresponding author: Nabiyah Bakhtawar, biyabakhtawar@gmail.com
}

\begin{abstract}
Anal fistula, or fistula-in-ano, is a condition involving the anal region that is common yet debilitating. Surgery is the mainstay of treatment for an anal fistula and the chances of recurrence are quite high even after corrective surgical procedures. The risk factors for recurrence can be broadly classified into four categories: 1) risk factors related to the fundamental anatomy of the fistula and presence of comorbidities, 2) lack of proper preoperative assessment of the fistula, which includes failure to recognize the internal opening and overall structure of the fistula and not supplementing the proctologic examination with sufficient imaging, 3) intraoperative loopholes that include improper procedure selection, inexperience of the surgeon, and failure to get rid of the entire tract along with its ramifications, and 4) lack of proper postoperative care in the early and late periods following the surgery.
\end{abstract}

The aim of this paper, therefore, is to highlight the factors that could increase the risk of recurrence in different types of anal fistulae. Once surgeons know these risk factors, they can anticipate any complication and detect recurrence early.

Categories: Gastroenterology, General Surgery, Anatomy

Keywords: anal fistula, fistula-in-ano, fistulotomy, fistula recurrence

\section{Introduction And Background}

Fistula-in-ano or anal fistula is a common yet debilitating condition involving the anal region. A fistula can be defined as an abnormal connection between two epithelized surfaces lined with granulation tissue. In around $80 \%$ of cases, anal fistulae are secondary to a cryptogenic (infectious) process involving the anal glands. Infection of the anal glands leads to abscess formation in the inter-sphincteric planes which can then bud in different directions. Once the tract reaches an epithelized surface, it completes a fistula [13]. The incidence of anal fistulae is highly variable. The incidence ranges from as low as $0.7 \%$ to as high as 37\% in different cases [4-11]. Males are twice as likely to develop an anal fistula compared to females [12]. The mean age of occurrence is 40 years [13-15].

Received 02/21/2019 Review began 02/27/2019 Review ended 03/05/2019 Published 03/07/2019

\section{() Copyright 2019}

Bakhtawar et al. This is an open access article distributed under the terms of the Creative Commons Attribution License CC-BY 3.0., which permits unrestricted use, distribution, and reproduction in any medium, provided the original author and source are credited.
Surgeons have long struggled to find an effective method to treat this cumbersome condition. The treatment of anal fistulae has seen many advancements. Still, the failure and recurrence rates are astoundingly high. The chances of recurrence in different types of anal fistulae range between 7\% and 50\% [16-18]. Therefore, most patients require multiple surgeries.

Due to a high failure rate in fistula operations and increased risk of recurrence, this condition needs to be studied in detail. Also, there is a need for probing into the factors that increase the risk of recurrence. A clear understanding of these risk factors could help surgeons take timely steps to prevent future complications, especially recurrence. The aim of this paper, therefore, is to shed some light on the factors that increase the risk of recurrence in cases of anal fistulae.

\section{Review}

\section{Factors increasing the risk of recurrence in anal fistulae}

The factors increasing the risk of recurrence of an anal fistula can be categorized as:

1. Factors related to the fistula anatomy and other comorbidities

2. Preoperative factors increasing the risk of recurrence

3. Intraoperative deficiencies leading to recurrence

4. Factors related to postoperative complications and care

1. Factors Related to the Fistula Anatomy and Other Comorbidities 
Park's classification is the most useful guide for the diagnosis and categorization of anal fistulae. According to this classification, anal fistulae can be classified into four groups: inter-sphincteric (type I), transsphincteric (type II), supra-sphincteric (type III), and extra-sphincteric (type IV). The supra-sphincteric and extra-sphincteric fistulae (type III and IV), though less common, are associated with a higher risk of complications and recurrence [17-19].

A supra-sphincteric fistula starts in the inter-sphincteric plane, continues in the same plane above the puborectalis muscle, and finally moves downward between the puborectalis and levator ani to enter the ischiorectal fossa [19]. In one study, all the patients with a supra-sphincteric fistula developed recurrence. In the same study, supra-sphincteric fistula alone contributed to $39 \%$ of cases of recurrence of all the fistula types studied [20].

The extra-sphincteric type is the rarest form of anal fistula. This fistula type has a unique anatomy as it lies completely outside the ring of sphincteric muscles. If this type of fistula is laid open, it would lead to total incontinence, incomplete closure, and consequently will have a higher risk of recurrence [18-19].

Another factor related to fistula anatomy that increases the risk of recurrence is the circumferential involvement of the fistula. This pattern leads to the formation of 'horse-shoe shaped' fistula [19]. Koehler et al. in 2004 carried out a research on surgical outcomes in a cohort of patients with horseshoe fistula-in-ano treated with primary closure. According to their experience, $81 \%$ of patients underwent multiple procedures. The recurrence rate, following different flap techniques, was as high as $35 \%$ [21].

The high extension of a fistula, with erroneous diagnosis and faulty treatment strategy, can also lead to recurrence. All forms of high extending fistulae are difficult to diagnose and manage; some forms are more challenging to deal with than the others. As illustrated by Park et al., inter-sphincteric fistulae with a high track opening into the Iower rectum, high inter-sphincteric fistulae without a perineal opening, and high inter-sphincteric fistulae with a pelvic extension are particularly difficult entities associated with a greater risk of complications and recurrence [19].

Besides the anatomical factors causing recurrent disease, several other comorbidities increase the risk of anal fistula recurrence. These factors include anal cancer [22], Crohn's disease [23], diabetes [24], smoking [25], and an immunosuppressed state like HIV [26].

\section{Preoperative Factors Increasing the Risk of Recurrence}

An anal fistula warrants a detailed proctological examination. Performing a proctoscopy is important for several reasons. First, it helps determine the tonus of anal sphincters. Second, it is important to identify the internal opening of the fistula. Finally, a detailed proctoscopy is important to exclude proctitis because of higher risk of recurrence if surgery is performed in the presence of proctitis [27-28].

The internal opening represents the source point of the fistulous pathology. Therefore, effective preoperative and intraoperative identification of the internal opening is crucial for successful treatment and for preventing recurrence. The internal opening of all fistulous tracts should be excised or drained and the wound formed should be left open to heal by secondary intention and to allow proper drainage [29].

The failure to recognize the internal opening preoperatively can lead to a substantial increase in the risk of recurrence. Andrzej et al. reported that the failure to recognize internal opening preoperatively causes a 20fold increase in the relative risk of fistula recurrence [30]. Therefore, a detailed proctological examination should be supplemented with proper imaging modalities. The success rates of rectal endoscopic ultrasound (EUS) and pelvic MRI in locating internal openings are 86\%-95.8\% and 90\%-96\%, respectively [31-32].

A fistula might be complex with multiple tracts and internal openings. At times, it is almost impossible to determine the exact anatomy and relationship of a fistula to the surrounding structures unless proper imaging is available [33-35]. Therefore, lack of proper preoperative imaging might lead to incomplete excision or drainage of the fistulous tract and possible recurrence.

The use of preoperactive rectal EUS is helpful in the case of primary fistulae. In such cases, rectal ultrasound (RUS) helps determine the type of fistula and its internal opening with high accuracy. It is also helpful in the preoperative assessment of anal sphincters. However, EUS is not of much value in cases of recurrent fistulae. That is because EUS is not helpful in differentiating between a scar from a previous fistula and active fistula. Moreover, it gives limited information about the structure of a fistula if the tract is away from the probe [36]. In such conditions, the use of techniques such as injecting hydrogen peroxide and performing MRI and 3D endosonography should be considered [37-39].

3. Intraoperative Factors Leading to Recurrence

The failure to complement clinical examination with proper imaging could increase the risk of recurrence 
due to some other reasons too. Looking for the internal opening in the absence of proper imaging is quite difficult even for a seasoned surgeon. An attempt to identify the fistulous opening intraoperatively might not be successful because the internal opening might be blocked due to the inflammation of perianal crypts. The use of hydrogen peroxide or a dye to look for the internal opening might also not be successful in such cases. Furthermore, an attempt to use a probe might complicate the situation further. While the gentle use of a probe could help identify the opening, forceful probing could lead to the formation of a false tract, which may even turn into a new fistula on its own (iatrogenic fistula) [40].

Several factors related to the experience of the surgeon performing the procedure are also important. It is important that the surgeon ensures complete course of the fistulous tract, including its ramifications. A failure to recognize and excise the complete fistulous tract can leave behind granulation tissue, which will lead to the persistence of the fistulous tract. Sangwan et al. studied the causes of recurrence in patients with 'simple' fistula-in-ano. Complex, fistulae due to Crohn's, supra-sphincteric, and extra-sphincteric fistulae were excluded from the study. Researchers found that at least $20 \%$ of cases of recurrence occurred due to a failure to excise the fistulous tract completely [41].

The problem of recurrence also arises when the surgeon puts aside the basic principles of proctological surgery and tries to emphasize on the cosmetic effects. If a surgeon follows the proctological principles, no matter how extensive the incision, the cosmetic results are quite satisfactory after healing. Therefore, the thought of cosmetic effects should not hold a surgeon back from properly excising or draining a fistula [42].

Moreover, the choice of surgical procedure is one of the most important intraoperative factors controlling the risk of recurrence. The details are summarized in Table 1.

\begin{tabular}{|l|l|}
\hline Procedure & Rate of Recurrence \\
\hline Fistulectomy & $9.5 \%[43]$ \\
\hline Simple fistulotomy & $12.5 \%[43]$ \\
\hline Cutting seton fistulotomy & $5 \%$ to $29 \%[44]$ \\
\hline Fibrin sealants & $69 \%[45]$ \\
\hline Anal fistula plugs & $32 \%[46]$ \\
\hline Flap procedures & $30 \%$ to $60 \%[47]$ \\
\hline
\end{tabular}

TABLE 1: A table summarizing the risk of recurrence in anal fistulae with different surgical approaches

4. Factors Related to Postoperative Complications and Care

The factors related to the postoperative care of the patients undergoing a fistula surgery have received limited attention. There is limited data that address the issues related to the potential postoperative complications and factors related to postoperative care that could contribute to the risk of recurrence of anal fistulae.

The following points related to the postoperative care of anal fistula treatment have been gathered through a literature search. Lack of these elements of care could potentially lead to an increased risk of recurrence $[42,48-50]$.

Early care (up to four to six weeks): Once operated, the anal canal takes at least six weeks to heal properly. During this period, a thorough medical examination should be performed at least once weekly to rule out potential complications. One of the main complications can be gas and/or fecal incontinence. A thorough examination should be done and the patient should be advised sphincter exercises [48-50].

The wound following anal canal surgery should be irrigated daily and dressing should be changed daily to avoid complications and recurrence. If a 'cutting' seton is applied, the patient should be instructed to start pulling on the thread from the fourth week after the surgery and if the doctor has cut the sphincter muscles, the doctor himself/herself will do that four to five weeks after the surgery [42,48-50].

The 'loose' setons can stay for a prolonged period. This increases the risk of formation of a fistulous tract around the seton itself. Therefore, care should be taken to irrigate the wound frequently to allow the healing of wound from the base and not from the skin [42,48-50]. 
Late care (after six weeks): A complete proctological examination should be carried out once every four weeks after the first six weeks of the procedure. This is to help detect early recurrence. A complete proctological examination is of utmost importance and it should be supplemented with a rectal ultrasound $[42,48-50]$.

Complicated fistulae, secondary to Crohn's disease or those that are high lying, will need seton placement for longer duration. The assessment and care for such fistulae should be more frequent and more rigorous $[42,48-50]$.

\section{Conclusions}

To conclude, an anal fistula is a cumbersome condition with a high rate of complications and recurrence. There are a number of risk factors that could possibly increase the chances of recurrence following anal fistula surgery. These risk factors include elements related to the basic anatomy of the fistula, the presence of comorbidities, lack of comprehensive preoperative assessment of the patient, flaws on part of the surgeon, poor choice of operation, and lack of postoperative care. The factors mentioned in this paper should be kept in mind and a surgeon should always anticipate the possible factors in reducing the risk of recurrence.

\section{Additional Information \\ Disclosures}

Conflicts of interest: In compliance with the ICMJE uniform disclosure form, all authors declare the following: Payment/services info: All authors have declared that no financial support was received from any organization for the submitted work. Financial relationships: All authors have declared that they have no financial relationships at present or within the previous three years with any organizations that might have an interest in the submitted work. Other relationships: All authors have declared that there are no other relationships or activities that could appear to have influenced the submitted work.

\section{References}

1. Whiteford MH, Kilkenny, Hyman N, et al.: Practice parameters for the treatment of perianal abscess and fistula-in-ano. Dis Colon Rectum. 2005, 48:1337. 10.1007/s10350-005-0055-3

2. Sugrue J, Nordenstam J, Abcarian H, Bartholomew A, Schwartz JL, Mellgren A, Tozer PJ: Pathogenesis and persistence of cryptoglandular anal fistula: a systematic review. Tech Coloproctol. 2017, 6:425-432. 10.1007/s10151-017-1645-5

3. Abcarian H: Anorectal infection: abscess-fistula. Clin Colon Rectal Surg. 2011, 24:14. 10.1055/s-00311272819

4. Shrum RC: Anorectal pathology in 1000 consecutive patients with suspected surgical disorders . Dis Colon Rectum. 1959, 2:469-472. 10.1007/BF02616939

5. Buda AM: General considerations of fistula in ano: the role of foreign bodies as causative factors . Am J Surg. 1941, 54:384-387. 10.1016/S0002-9610(41)90385-9

6. Choi YS, Kim DS, Lee DH, et al.: Clinical characteristics and incidence of perianal diseases in patients with ulcerative colitis. Ann Coloproctol. 2018, 34:138-143. 10.3393/ac.2017.06.08

7. Sainio P: Fistula-in-ano in a defined population. Incidence and epidemiological aspects . Ann Chir Gynaecol. 1984, 73:219-224.

8. Nelson R: Anorectal abscess fistula: what do we know?. Surg Clin North Am. 2002, 82:1139-1151. 10.1016/S0039-6109(02)00063-4

9. Ramanujam PS, Prasad ML, Abcarian H, Tan AB: Perianal abscesses and fistulas. A study of 1023 patients . Dis Colon Rectum. 1984, 27:593-597. 10.1007/BF02553848

10. Scoma JA, Salvati EP, Rubin RJ: Incidence of fistulas subsequent to anal abscesses . Dis Colon Rectum. 1974, 17:357-359. 10.1007/BF02586982

11. Vasilevsky CA, Gordon PH: The incidence of recurrent abscesses or fistula-in-ano following anorectal suppuration. Dis Colon Rectum. 1984, 27:126-130. 10.1007/BF02553995

12. Read DR, Abcarian H: A prospective survey of 474 patients with anorectal abscess . Dis Colon Rectum. 1979, 22:566-568. 10.1007/BF02587008

13. Hill JR: Fistulas and fistulous abscesses in the anorectal region: personal experience in management . Dis Colon Rectum. 1967, 10:421-434. 10.1007/BF02616813

14. Mazier W: The treatment and care of anal fistulas: a study of 1,000 patients . Dis Colon Rectum. 1971, 14:134-144. 10.1007/BF02560060

15. Piazza DJ, Radhakrishnan J: Perianal abscess and fistula-in-ano in children . Dis Colon Rectum. 1990, 33:1014-1016. 10.1007/BF02139215

16. Li J, Yang W, Huang Z, Mei Z, Yang D, Wu H, Wang Q: Clinical characteristics and risk factors for recurrence of anal fistula patients. [Article in Chinese]. Zhonghua Wei Chang Wai Ke Za Zhi. 2016, 19:1370-1374.

17. Garcia-Aguilar J, Belmonte C, Wong WD, Goldberg SM, Madoff RD: Anal fistula surgery. Factors associated with recurrence and incontinence. Dis Colon Rectum. 1996, 39:723-729. 10.1007/BF02054434

18. Dudukgian H, Abcarian $\mathrm{H}$ : Why do we have so much trouble treating anal fistula? . World J Gastroenterol. 2011, 17:3292-3296. 10.3748/wjg.v17.i28.3292

19. Parks AG, Gordon PH, Hardcastle JD: A classification of fistula in ano . Br J Surg. 1976, 63:1-12. 10.1002/bjs.1800630102

20. Khadia M, Muduli IC, Das SK, Mallick SN: Management of fistula-in-ano with special reference to ligation of 
intersphincteric fistula tract. Niger J Surg. 2016, 22:1-4. 10.4103/1117-6806.169818

21. Koehler A, Risse-Schaaf A, Athanasiadis S: Treatment for horseshoe fistulas-in-ano with primary closure of the internal fistula opening: a clinical and manometric study. Dis Colon Rectum. 2004, 47:1874-82. 10.1007/s10350-004-0650-8

22. Salati SA, Al Kadi A: Anal cancer - a review . Int J Health Sci (Qassim). 2012, 6:206-230. 10.12816/0006000

23. Hermann J, Eder P, Banasiewicz T, Matysiak K, Łykowska-Szuber L: Current management of anal fistulas in Crohn's disease. Prz Gastroenterol. 2015, 10:83-88. 10.5114/pg.2015.49684

24. Hamadani A, Haigh PI, Liu IL, Abbas MA: Who is at risk for developing chronic anal fistula or recurrent anal sepsis after initial perianal abscess?. Dis Colon Rectum. 2009, 52:217-21. 10.1007/DCR.0b013e31819a5c52

25. Ellis CN, Clark S: Effect of tobacco smoking on advancement flap repair of complex anal fistulas . Dis Colon Rectum. 2007, 50:459-63. 10.1007/s10350-006-0829-2

26. Papavramidis TS, Pliakos I, Charpidou D, et al.: Management of an extrasphincteric fistula in an HIVpositive patient by using fibrin glue: a case report with tips and tricks. BMC Gastroenterol. 2010, 10:18. 10.1186/1471-230X-10-18

27. Geltzeiler CB, Wieghard N, Tsikitis VL: Recent developments in the surgical management of perianal fistula for Crohn's disease. Ann Gastroenterol. 2014, 27:320-330.

28. Nordgren S, Fasth S, Hultén L: Anal fistulas in Crohn's disease: incidence and outcome of surgical treatment. Int J Colorectal Dis. 1992, 7:214-8. 10.1007/BF00341224

29. Dziki A, Bartos M: Seton treatment of anal fistula:experience with a new modification . Eur J Surg. 1998, 164:543-548. 10.1080/110241598750005930

30. Sygut A, Mik M, Trzcinski R: How the location of the internal opening of anal fistulas affect the treatment results of primary transsphincteric fistulas. Langenbecks Arch Surg. 2010, 395:1055-1059. 10.1007/s00423009-0562-0

31. Dwarkasing S, Hussain SM, Krestin GP: Magnetic resonance imaging of perianal fistulas. Semin Ultrasound CT MR. 2005, 26:247-58. 10.1053/j.sult.2005.04.004

32. Ratto C, Grillo E, Parello A, Costamagna G, Doglietto GB: Endoanal ultrtrasound-guided surgery for anal fistula. Endoscopy. 2005, 37:722-728. 10.1055/s-2005-870155

33. Waniczek D, Adamczyk T, Arendt J, Kluczewska E, Kozińska-Marek E: Usefulness assessment of preoperative MRI fistulography in patients with perianal fistulas. Pol J Radiol. 2011, 76:40-44.

34. Torkzad MR, Karlbom U: MRI for assessment of anal fistula. Insights Imaging. 2010, 1:62-71. 10.1007/s13244-010-0022-y

35. Gage KL, Deshmukh S, Macura KJ, Kamel IR, Zaheer A: MRI of perianal fistulas: bridging the radiologicsurgical divide. Abdom Imaging. 2013, 38:1033-1042. 10.1007/s00261-012-9965-4

36. Kim MJ: Transrectal ultrasonography of anorectal diseases: advantages and disadvantages . Ultrasonography. 2015, 34:19-31. 10.14366/usg.14051

37. Halligan S, Stoker J: Imaging of fistula in ano. Radiology. 2006, 239:18-33. 10.1148/radiol.2391041043

38. Dwarkasing S, Hussain S, Krestin G: Magnetic resonance imaging of perianal fistulas . Semin Ultrasound CT MRI. 2005, 26:247-258. 10.1053/j.sult.2005.04.004

39. Rankin RN, Fenster A, Downey DB, Munk PL, Levin MF, Vellet AD: Three-dimensional sonographic reconstruction: techniques and diagnostic applications. AJR. 1993, 161:695-702. 10.2214/ajr.161.4.8372741

40. Sygut A, Dziki A: Modern diagnostics and treatment of anal fistulas. Pol Przegl. 2004, 76:1194-1208.

41. Sangwan YP, Rosen L, Riether RD, Stasik JJ, Sheets JA, Khubchandani IT: Is simple fistula-in-ano simple? . Dis Colon Rectum. 1994, 37:885-9. 10.1007/BF02052593

42. Kolodziejczak M, Sudol-Szopinska I: Causes of recurrences of anal fistulae. New Medicine. 2005, 4:54-56.

43. Kronborg O: To lay open or excise a fistula-in-ano: a randomized trial . Br J Surg. 1985, 72:970. 10.1002/bjs.1800721211

44. Vial M, Parés D, Pera M, Grande L: Faecal incontinence after Seton treatment for anal fistulae with and without surgical division of internal anal sphincter: a systematic review. Colorectal Dis. 2010, 12:172-178. 10.1111/j.1463-1318.2009.01810.x

45. Loungnarath R, Dietz DW, Mutch MG, Birnbaum EH, Kodner IJ, Fleshman JW: Fibrin glue treatment of complex anal fistulas has low success rate. Dis Colon Rectum. 2004, 47:432-436. 10.1007/s10350-003-0076-8

46. Schwandner T, Roblick MH, Kierer W, Brom A, Padberg W, Hirschburger M: Surgical treatment of complex anal fistulas with the anal fistula plug: a prospective, multicenter study. Dis Colon Rectum. 2009, 52:15781583. 10.1007/DCR.0b013e3181a8fbb7

47. Bubbers EJ, Cologne KG: Management of complex anal fistulas. Clin Colon Rectal Surg. 2016, 29:43-49. 10.1055/s-0035-1570392

48. Tabry H, Farrands PA: Update on anal fistulae: surgical perspectives for the gastroenterologist . Can J Gastroenterol. 2011, 25:675-680.

49. Balogh G: Tube loop (Seton) drainage treatment of recurrent extrasphincteric perianal fistulae . Am J Surg. 1999, 177:147-149. 10.1016/S0002-9610(98)00322-5

50. Rickard MJ: Anal abscesses and fistulas. ANZ J Surg. 2005, 75:64-72. 10.1111/j.1445-2197.2005.03280.x 